\title{
Urgences
}

\section{Noël Audet, La Parade, Montréal, Québec/Amérique, 1984.}

\section{Françoise Daigle}

Numéro 12, 3e trimestre 1984

Spécial humour

URI : https://id.erudit.org/iderudit/025190ar

DOI : https://doi.org/10.7202/025190ar

Aller au sommaire du numéro

Éditeur(s)

Urgences

ISSN

0226-9554 (imprimé)

1927-3924 (numérique)

Découvrir la revue

Citer ce compte rendu

Daigle, F. (1984). Compte rendu de [Noël Audet, La Parade, Montréal,

Québec/Amérique, 1984.] Urgences, (12), 78-80. https://doi.org/10.7202/025190ar

Ce document est protégé par la loi sur le droit d'auteur. L'utilisation des services d’Érudit (y compris la reproduction) est assujettie à sa politique d'utilisation que vous pouvez consulter en ligne.

https://apropos.erudit.org/fr/usagers/politique-dutilisation/
Cet article est diffusé et préservé par Érudit.

Érudit est un consortium interuniversitaire sans but lucratif composé de l’Université de Montréal, l’Université Laval et l’Université du Québec à Montréal. Il a pour mission la promotion et la valorisation de la recherche. https://www.erudit.org/fr/ 
liser" beaucoup...

Cette obsession, commune à tous les personnages, occulte les autres situations dramatiques. Le départ de Marie, le détachement des soeurs et la vente de la maison n'ont pas de poids. Reste la relation avec Julie où le personnage-narrateur s'investit le plus émotivement. Il y a là la matière d'un roman érotique. Mais il ne suffit pas de voir et de nommer les parties d'une anatomie pour produire un effet d'érotisme. La sensation est souvent absente de ces descriptions que j'ai trouvées techniques et par conséquent froides.

L'inceste, ce comportement caché et peu expliqué, serat-il mieux compris ou permettra-t-il d'ouvrir de nouvelles voies? Pas vraiment, si ce n'est le changement radical de Julie devenue "une fille comme toutes les autres filles" (p. 226), avec un appartement à elle, un travail, un ami et des activités intéressantes.

Martine Lemieux

LA PARADE, de Noël Audet, Ed. Québec Amérique, 1984.

II y a des enthousiasmes qui ne pardonnent pas... Comme c'est coupe-gorge, parfois, un bon premier roman!

Ayant beaucoup aimé Quand la voile faseille, premier roman de Noël Audet, c'est avec plaisir que j'ai accepté de lire ce troisième roman, La Parade. Hélas! en migrant à la ville, l'écriture a aussi perdu sa belle vitalité... Si, dans I'univers gaspésien, les mots jouaient à saute-mouton, se bousculaient, s'amusaient à des bonheurs d'expression tout à fait savoureux; si la parole y culbutait et y pirouettait comme une acrobate, ici... les jeux de mots, presque forcés, prennent des allures anémiques (à vous de juger: "mon père putatif (Le Tif à putes)" (page 13) ou encore "son mascara - Ton masque-à-rat coule!" (page 87). Les personnages eux-mêmes, touchés par la contagion, se comprennent à coups de "hé! hé!" et de 
"hum", dans le style "tsé-veux-dire" le plus pur, et s'exclament: "On sait ce que parler veut dire!" (p. 31). Enfin, si l'auteur fait de l'ironie au dépend de ses personnages, comment ne pas se sentir impatienté soi-même... Impatienté par ce bègue incroyablement bavard dont le discours ouvre le roman en une longue, longue digression... Impatienté par ce narrateur fuyant, caché tour à tour derrière chaque personnage, passant du je au tu ou au il sans cohérence - quand on ne supprime pas carrément le pronom, procédé suremployé dans les premiers chapitres. Maladresse voulue pour nous montrer le langage atrophié des citadins? L'exhibitionnisme reste quand même agaçant.

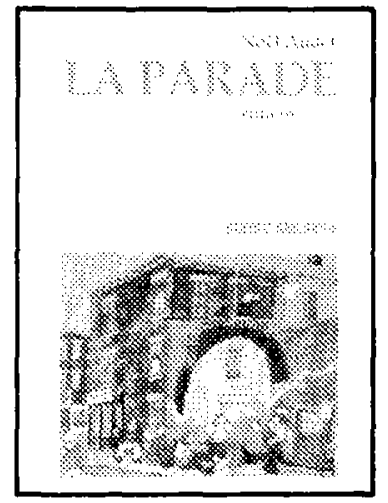

Cherchant alors une balise, le lecteur s'attarde à l'intrigue, ou aux personnages. L'intrigue est invraisemblable mais c'est là un péché bien pardonnable, et même, cela peut devenir fort intéressant. Peut? Pourrait... Cela pourrait être drôle, léger, si l'on avait pas irrémédiablement l'impression que ce "Grand Projet" n'est qu'un prétexte pour l'auteur: un alibi pour faire une revue disparate des événements politiques des dernières décennies. Entre les événements d'octobre 70 et Mirabel, des personnages sans consistance s'agitent... Car si, dans Quand la voile... les personnages esquissés prenaient la densité du silence et du non-dit, ceux de La Parade n'ont pas l'air, eux, d'avoir grand-chose à dire en dehors de leurs formules toutes faites. Et je n'arrive pas à ressentir ni sympathie ni tendresse pour eux. Et tiens, pour ne pas les trahir, je leur laisse la parole: 
Le bègue: "Maudites cruches de maudits bouchés. Et le grand orignal à panache Henri, sa grosse gueule baveuse sous son nez à trous de trompette (...). Mal au ventre tellement l'envie soudaine de lui pisser dans sa gueule d'orignal clouée au mur." (p. 18).

Ti-Pop: "Connaissez-vous la différence entre une femme et une pizza? C'est... c'est... la deuxième, il faut la faire venir pour la manger..." (p. 116).

Vous ressentez de la tendresse, vous?

Et les personnages féminins, là-dedans... Gabrielle, qui n'a jamais rien fait d'autre de sa vie qu'une courtepointe et qui en tire toute sa gloire; Florence, qui, nous apprend-t-on, à l'ineffable chance d'avoir "un cul mythique, un cul Penthouse Mayfair Genesis, à trois dimensions, pas sur papier glacé, pas du toc, dans l'épaisseur." (p. 44). Reste la femme de Johnny le politicien: “Johnny n'avait qu'à paraitre, à frapper la table du poing ou à hurler dans un micro pour qu'elle entre en transe. Aucune ombre ne pouvait plus altérer sa joie rayonnante. Elle secondait son mari comme on va à la messe, le genou poli et la tête vide." (p. 164). Madame Alleluia, pauvre gourde, tu aurais du rester chez toi, faire du petit point ou de la courtepointe comme cette chère Gabrielle, c'eut été plus naturel, et qui sait? Tu aurais peut-être hérité d'un paragraphe plus élogieux!

Bref, le personnage le mieux réussi de La Parade, c'est encore Montréal même. C'est lorsque l'auteur s'oublie un instant dans les descriptions qu'il retrouve sa verve. Ah! si La Parade n'était qu'un premier roman! Si Noël Audet n'avait déjà fait infiniment mieux!

II ne nous reste plus qu'à souhaiter que le prochain roman soit mieux réussi - moins agressant et moins vide. Quant à savoir si je serai toujours du nombre des lecteurs...

II y a aussi des déceptions qui ne pardonnent guère.

Françoise Daigle 